Conclusion: We demonstrated that the prevalence of CVD is approximately 1.5 times higher in patients with rheumatic diseases compared to healthy controls ( $11 \%$ vs. $7 \%$, respectively). This corresponds with previous research, although the reported prevalence of CVD in PSA and AS patients is even higher compared to prior studies. This suggests that the CVD risk of patients with rheumatic diseases is still elevated in 2020 compared to the general population, despite the improved management of rheumatic disease activity. Therefore, adequate and timely treatment of $\mathrm{CV}$ risk factors remains relevant, not only in patients with $\mathrm{RA}$, but in patients other rheumatic diseases as well.

REFERENCES:

[1] Hooijberg F et al. (2020) Patients with rheumatic diseases adhere to COVID19 isolation measures more strictly than the general population. The Lancet rheumatology 2(10), 583-585.

Disclosure of Interests: None declared

DOI: 10.1136/annrheumdis-2021-eular.1739

\section{POS0525 $\quad$ ARTHRITIC PAIN AS A SURROGATE MARKER FOR ASYMPTOMATIC CARDIOVASCULAR RISK FACTORS: OFFERING PRACTITIONERS A 'TEACHABLE MOMENT'}

J. Sewell ${ }^{1}$, S. M. Hussain ${ }^{1}$, Y. Wang ${ }^{1}$, A. Wluka ${ }^{1}$, M. Carrrington ${ }^{2}$, K. Samaras ${ }^{3}$, F. Cicuttini . ' ${ }^{1}$ Monash University, Department of Epidemiology and Preventive Medicine, School of Public Health and Preventive Medicine, Melbourne, Australia; ${ }^{2}$ Baker Heart and Diabetes Institute, Pre-Clinical Disease and Prevention, Melbourne, Australia; ${ }^{3}$ University of New South Wales, St Vincent's Clinical School of Medicine, Sydney, Australia

Background: Cardiovascular diseases (CVD) are the number one cause of death worldwide. CVDs are linked to well established risk factors: obesity, hypertension (HTN), dyslipidaemia (DL) and diabetes mellitus (DM) ${ }^{1}$. While targeting risk factors reduces the burden of CVD, this is often challenging because they are largely asymptomatic and patients are therefore unlikely to seek medical attention. Arthritis, in contrast, causes pain and functional impairment prompting presentation to a healthcare practitioner. Patients with arthritis of varying aetiologies (such as osteoarthritis ${ }^{2}$, gout ${ }^{3}$, rheumatoid arthritis ${ }^{4}$ ) have been shown to have an increased risk of CVD.

Objectives: To examine the relationship between arthritis and DM, HTN and DL in adults of all age groups. A secondary objective was to examine whether this relationship existed independent of obesity.

Methods: Data from the 2017-18 Australian Bureau of Statistics National Health Survey included 13,776 participants, categorised into young (18-39 years), middle aged (40-64 years) and older ( $\geq 65$ years) adults. Blood pressure, height and weight were measured. BMI was calculated and participants classified as obese $\left(\geq 30 \mathrm{~kg} / \mathrm{m}^{2}\right)$ or non-obese. HTN was defined as $>140 / 90 \mathrm{mmHg}$. Participants were asked if they had arthritis of any form, DL or DM diagnosed by a doctor. Logistic regression models estimated odds ratios with $95 \% \mathrm{Cl}$ for prevalence of arthritis associated with CVD risk factors.

Results: Arthritis was reported by $3.9 \%$ of young adults, $28.8 \%$ of middle-aged adults, and $54.5 \%$ ofolderadults. In all three age groups, arthritis was associated with significantly increased odds of obesity, HTN, DL and DM. For example, in middle-aged adults, having arthritis was associated with increased odds of obesity $(1.75,95 \% \mathrm{Cl} 1.54-2.01)$, HTN (1.78, 1.60-2.04), DL (2.14, 1.84-2.49) and DM (1.64, 1.33-2.03). These associations remained statistically significant after adjustment for obesity.

Conclusion: Compared to those without arthritis, adults with arthritis were at increased risk of obesity, HTN, DM and DL. The increased risk of HTN, DM and DL was independent of obesity and tended to be higher in younger adults. These data suggest that a patient's presentation with symptomatic arthritis of any aetiology and at any age, may be used opportunistically as a "teachable moment" for screening for asymptomatic CVD risk factors in higher-risk individuals. This provides practitioners an opportunity to manage both arthritis and CVD risk in parallel, rather than in silos.

REFERENCES:

[1] World Health Organisation. (2017). "Cardiovascular Diseases." from https://www.who.int/en/news-room/fact-sheets/detail/cardiovasculardiseases(cvds).

[2] Wang, H., et al. (2016). "Osteoarthritis and the risk of cardiovascular disease: a meta-analysis of observational studies." Scientific reports 6: 39672.

[3] Singh, J. (2015). "When gout goes to the heart: does gout equal a cardiovascular disease risk factor?" Annals of the Rheumatic Diseases 74: 631-634.

[4] England, B. R., et al. (2018). "Increased cardiovascular risk in rheumatoid arthritis: mechanisms and implications." British Medical Journal 361: k1036.
Table 1. Prevalence of CVD risk factors in adults with and without arthritis.

\begin{tabular}{|c|c|c|c|c|c|c|c|c|c|}
\hline & \multicolumn{3}{|c|}{ Young $18-39$ yo } & \multicolumn{3}{|c|}{ Middle Aged 40-64 yo } & \multicolumn{3}{|c|}{ Older $\geq 65$ yo } \\
\hline & $\begin{array}{c}\text { No } \\
\text { arthritis } \\
\mathbf{n}= \\
3773\end{array}$ & $\begin{array}{l}\text { Arthritis } \\
n=157\end{array}$ & $\begin{array}{c}\text { OR } \\
(95 \% \mathrm{Cl}) \\
\text { *adjusted } \\
\text { for obesity }\end{array}$ & $\begin{array}{c}\text { No } \\
\text { arthritis } \\
n= \\
4055\end{array}$ & $\begin{array}{r}\text { Arthritis } \\
n=1638\end{array}$ & $\begin{array}{c}\text { OR } \\
\text { (95\% Cl) } \\
\text { *adjusted } \\
\text { for } \\
\text { obesity }\end{array}$ & $\begin{array}{c}\text { No } \\
\text { arthritis } \\
n= \\
1891\end{array}$ & $\begin{array}{r}\text { Arthritis } \\
\mathrm{s} n=2262\end{array}$ & $\begin{array}{c}\text { OR } \\
(95 \% \mathrm{Cl}) \\
\text { *adjusted } \\
\text { for obesity }\end{array}$ \\
\hline Obesity & 473 & 32 & $\begin{array}{c}2.07 \\
(1.36-3.16)\end{array}$ & 868 & 527 & $\begin{array}{c}1.75 \\
(1.54-2.01)\end{array}$ & 326 & 610 & $\begin{array}{c}1.89 \\
(1.62-2.21)\end{array}$ \\
\hline HTN & 131 & 14 & $\begin{array}{c}2.72 \\
(1.53-4.84) \\
2.35 \\
(1.17-4.70)^{*}\end{array}$ & $\begin{array}{r}745 \\
+\quad\end{array}$ & 496 & $\begin{array}{c}1.78 \\
(1.60-2.04) \\
1.59 \\
(1.37-1.84)\end{array}$ & 730 & 1091 & $\begin{array}{c}1.48 \\
(1.31-1.68) \\
1.35 \\
(1.18-1.55)^{\star}\end{array}$ \\
\hline DM & 19 & 4 & $\begin{array}{c}5.7 \\
(1.74-15.37) \\
4.87(1.34- \\
17.69))^{*}\end{array}$ & $\begin{array}{l}236 \\
+\end{array}$ & 151 & $\begin{array}{c}1.64 \\
(1.33-2.03) \\
1.37 \\
(1.08-1.73)^{\star}\end{array}$ & $\begin{array}{l}256 \\
*\end{array}$ & 399 & $\begin{array}{c}1.37 \\
(1.15-1.62) \\
1.15(0.95- \\
1.39)^{\star}\end{array}$ \\
\hline
\end{tabular}

Disclosure of Interests: None declared

DOI: 10.1136/annrheumdis-2021-eular.1763

\section{\begin{tabular}{|l|l}
\hline POS0526 & SEXUAL FUNCTION IN MALE AND FEMALE PATIENTS
\end{tabular} WITH RHEUMATOID ARTHRITIS: A POST-HOC ANALYSIS OF THE FINCH STUDIES}

L. F. Perez-Garcia ${ }^{1}$, M. Micu ${ }^{2}$, L. Gheyle ${ }^{3}$, Z. Yin ${ }^{4}$, Y. Tan ${ }^{5}$, K. Chen ${ }^{6}$, P. Papazian ${ }^{7,8}$, K. Van Beneden ${ }^{9}$, R. Dolhain ${ }^{1}$, R. Westhovens ${ }^{10}$. ${ }^{1}$ Erasmus University Medical Centre, Department of Rheumatology, Rotterdam, Netherlands; ${ }^{2}$ Rehabilitation Clinical Hospital, Rheumatology Division, 2nd Rehabilitation Department, Cluj-Napoca, Romania; ${ }^{3}$ Galapagos NV, Clinical Research, Mechelen, Belgium; ${ }^{4}$ Gilead Sciences, Inc., Department of Clinical Data Science, Foster City, United States of America; ${ }^{5}$ Gilead Sciences, Inc., Clinical Research (Inflammation Therapeutic Area), Foster City, United States of America; ${ }^{6}$ Gilead Sciences, Inc., Department of Clinical Data Science, Foster City, United States of America; ${ }^{7}$ Pitié-Salpêtrière Hospital, Infectious Diseases Department, Paris, France; ${ }^{8}$ Galapagos France, Medical Affairs, Puteaux, France; ${ }^{9}$ Galapagos NV, Medical Affairs, Mechelen, Belgium; ${ }^{10}$ University Hospitals Leuven, Department of Development and Regeneration, Skeletal Biology and Engineering Research Centre, Division of Rheumatology, Leuven, Belgium

Background: While sexual function is impaired in a high proportion of patients with rheumatoid arthritis (RA), it is often neglected in patient care. ${ }^{1} \mathrm{FINCH} 1$ (NCT02889796), FINCH 2 (NCT02873936) and FINCH 3 (NCT02886728) were Phase 3 studies to assess the safety and efficacy of filgotinib (FIL) for moderate-to-severe RA; patient-reported sexual function was also evaluated

Objectives: To analyse disease characteristics associated with sexual function and explore the effect of FIL and adalimumab (ADA) on sexual function in males and females in the FINCH studies.

Methods: Post-hoc analyses included data from patients who were randomised and received $\geq 1$ dose of study drug in the $\mathrm{FINCH}$ studies. Male and female subgroup analyses were performed to describe the correlation between baseline disease characteristics and baseline visual analogue scale (VAS) sexual function score (using Pearson correlation coefficient) and to assess the treatment effect on the change from baseline in VAS sexual function $(\mathrm{mm})$ up to Week 52 (FINCH 1 and 3 ) or Week 24 (FINCH 2). Patients indicated how RA affected their ability to have sex during the last week using an exploratory 0-100 VAS (0: no effect; 100: complete inhibition). Changes from baseline were analysed with a mixed-effects model for repeated measures. All $P$ values are nominal for exploratory purposes.

Results: Baseline characteristics are shown in the Table 1. Univariate analyses revealed significant positive correlations $(P<0.05)$ between disease duration and baseline VAS sexual function score in male and female subgroups in $\mathrm{FINCH}$; no significant correlations were seen in male and female subgroups of $\mathrm{FINCH}$ 2 and 3 . In all studies, significant correlations $(P<0.05)$ were observed between baseline VAS sexual function score and baseline disease characteristics (swollen/tender joint count 28, Disease Activity Score-28, Health Assessment Questionnaire Disability Index, 36-Item Short Form Survey, patient global VAS, pain VAS or fatigue) in males or females. In all studies, analysis of least-squares mean changes from baseline in VAS sexual function revealed improvements in both males and females on FIL as early as Week 2, until Week 52 (Week 24 in FINCH 2). Figure 1 shows data for FINCH 1.

Conclusion: Sexual function should be considered as an important patient outcome in RA treatment. At baseline in the FINCH studies, disease activity 